\title{
Impact of Immigration on Complementary and Alternative Medicine Use in Hispanic Patients
}

\author{
Brett White, MD, Lyndee Knox, PhD, Monica Zepeda, MPH, Dennis Mull, MD, and
} Felix Nunez, MD, MPH

Background: Although previous research has demonstrated frequent complementary and alternative medicine (CAM) use by Hispanic patients, it remains unclear whether the status of immigration plays a role in the frequency and reasons for use.

Methods: A survey of 164 patients from a federally qualified health center in South Central Los Angeles was used; the health center serves a predominantly Latino immigrant patient population. The study included the following variables: patient age; sex; place of birth; number of years living in the United States; CAM use within the last year; and, if positive CAM use, what type(s) and for what condition(s).

Results: Sixty-six percent of patients had used a CAM substance within the past year. Ninety-seven percent of the patients were immigrants (primarily from Mexico, El Salvador, and Guatemala). Differences in CAM use between recently arrived ( $\leq 9$ years) and long-term immigrants ( $\geq 10$ years) were not significant. Ninetyfour percent of patients using CAM reported using herbal/tea/plant-based substances, with the most frequent reason for CAM use being digestive problems. Although most CAM substances were obtained from a market (64\%), a not insignificant number of CAM substances were grown at home (23\%).

Conclusions: Time since immigration does not seem to impact the frequency of CAM use by Hispanic immigrant patients. Herbal/tea/plant-based substances are frequently used in the Hispanic patient population, often for digestive complaints. (J Am Board Fam Med 2009;22:337-8.)

Previous research has demonstrated that the Hispanic population frequently uses complementary and alternative medicine (CAM) ${ }^{1,2}$ with higher utilization rates among those Hispanic patients with chronic diseases. ${ }^{3}$ Studies have also revealed that Hispanic patients tend to have high provider nondisclosure rates, in some cases up to $82 \% .{ }^{1}$ It remains unclear whether the status of immigration plays a role in the frequency and reasons for use. This research project examined this novel issue among the Hispanic patient population.

\section{Methods}

A survey was conducted at a federally qualified health center in inner-city Los Angeles, California.

This article was externally peer reviewed.

Submitted 6 October 2008; revised 10 December 2008; accepted 15 December 2008.

From the Department of Family Medicine, Keck School of Medicine, University of Southern California.

Funding: none.

Conflict of interest: none declared.

Corresponding author: Brett White, MD, USC Keck School of Medicine, 1510 San Pablo St, Suite 104, Los Angeles, CA 90033 (E-mail: brettwhitemd@gmail.com).
The survey tool was translated into Spanish and consisted of the following items: age, sex, place of birth, number of years living in the United States, CAM use within the last year, and, if positive CAM use, what type(s) and for what condition(s). All adult Latino patients aged 18 and older seeking care during a 2 -week period were surveyed by a medical assistant during the previsit encounter. Only those patients who had self-identified as Latino were included. Use of the Spanish or English survey by the medical assistant was determined by patient's language preference at the time of intake. The response rate was $100 \%$. Completion of the survey was voluntary and there were no incentives provided to the patients.

For analysis, CAM products were grouped into 7 categories: (1) herbal/tea/plant-based; (2) diet-related; (3) vitamins/minerals; (4) over-the-counter medications; (5) other supplements (such as Glucosamine and MSM); and (6) unknown/unrecognized CAMs.

Symptoms or reasons for use of CAMs were grouped into 12 different bodily system categories: digestive, nervous, immune, circulatory, endocrine, 
Table 1. Reasons for Use in Patients Reporting the Use of Complementary and Alternative Medicines $(\mathbf{n}=$ 109)

\begin{tabular}{lc}
\hline Illness Category & Patients (\%) \\
\hline Digestive & 47.2 \\
No illness & 23.1 \\
Nervous & 17.6 \\
Immune & 16.7 \\
Circulatory & 11.1 \\
Endocrine & 11.1 \\
Reproductive & 9.3 \\
Skeletal & 7.4 \\
Urinary & 3.7 \\
Muscular & 2.8 \\
Cardiovascular & 0.9 \\
Other & 1.9 \\
\hline
\end{tabular}

reproductive, skeletal, urinary, muscular, cardiovascular, and other. Pearson's $\chi^{2}$ was used to test for differences in CAM use between recent immigrants and long-term immigrants to the United States. Approval was obtained from the University of Southern California Health Science Institutional Review Board.

\section{Results}

A total of 164 patients completed the survey. Sixtysix percent (108) of patients were immigrants from Mexico, 17\% (28) were from El Salvador, and 10\% (17) were from Guatemala. Only 5 patients (3.0\%) were born in the United States. Other countries of origin included Nicaragua, Argentina, Cuba, Ecuador, and Honduras. Twenty-two percent (32) reported being in the United States $\leq 9$ years and $78 \%$ (116) reported living in the United States $\geq 10$ years.

Sixty-six percent (109) of patients reported using at least one CAM product in the past year. Ninetyfour percent (103) of patients using CAM reported using herbal/tea/plant-based substances, $7 \%$ (8) used vitamin supplements, and 4\% (4) used a recognized weight-loss supplement. The most frequent reason patients gave for using CAM products was digestive problems (47\%) (see Table 1).
Of the 250 CAM substances patients reported using, 64\% ( $\mathrm{n}=160)$ were purchased from a store or market; $23 \%(\mathrm{n}=58)$ were grown at home; $6 \%$ $(\mathrm{n}=15)$ were purchased from pharmacias, yerberias, or boticas (specialty herb shops); and the remaining $7 \%(\mathrm{n}=17)$ came from sources including television commercials, doctors/physicians, and from out of the country. Differences in CAM use between recently arrived ( $\leq 9$ years) and long-term immigrants ( $\geq 10$ years) were not significant $\left(\chi^{2}=2.712\right.$; $P=.10)$.

\section{Discussion}

Findings of the current study are consistent with previous research showing that CAM use is common among Latino patients. Herbal/tea/plantbased substances were the most frequently reported, with digestive complaints being the most frequent reason reported for CAM use.

Although there was an assumption by clinicians in the research group that CAM use would be carried over from traditional practices in the country of origin and more frequently used by recent immigrants, this hypothesis was not supported by the current study. Patients who had resided in the United States for 10 years or more were as likely to use CAM products as their more recently arrived counterparts. This finding underscores the importance of asking all patients about their CAM use and avoiding assumptions about whether patients are using CAM substances based on how recently they have immigrated.

\section{References}

1. Nasser M, Wali S, Ziment I. Use of alternative medicine among Hispanics. J Altern Complement Med 2004;1:851-9.

2. Graham RE, Ahn AC, Davis RB, O'Connor BB, Eisenberg DM, Phillips RS. Use of complementary and alternative therapies among racial and ethnic minority adults: results from the 2002 National Health Interview Survey. J Natl Med Assoc 2005;97: $535-45$.

3. Egede LE, Ye X, Zheng D, Silverstein MD. The prevalence and pattern of complementary and alternative medicine use in individuals with diabetes. Diabetes Care 2002;25:324-9. 